INTERNATIONAL DESIGN CONFERENCE - DESIGN 2018

https://doi.org/10.21278/idc.2018.0166

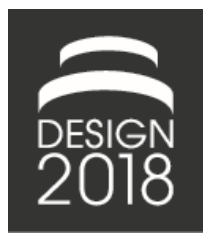

\title{
A KNOWLEDGE-BASED AND MULTI-USER PLATFORM FOR PRESCRIBING CUSTOM-MADE INSOLES
}

\author{
A. Brunzini, M. Mandolini, M. Germani, C. J. Nester and A. E. Williams
}

\begin{abstract}
This paper presents a knowledge-based method and relative multi-user web platform to prescribe Custom Made Insoles (CMI) involving the various stakeholders (patients/customers, practitioners, manufacturers and controllers) in an integrated approach that covers the entire process. The CMI prescription and design are carried out by using configuration rules, which combine foot parameters with insoles features. The platform also offers functionalities to collect and monitor the patients feedbacks, to control the clinician work and to obtain an electronic insole order used by manufactures.
\end{abstract}

Keywords: co-design, design knowledge, healthcare design, knowledge-based process, custom-made insole

\section{Introduction}

The knowledge-based collaborative platform presented in this paper has been developed in order to overcome a relevant problem: the lack of knowledge-based software tools which can support the whole Custom-Made Insoles (CMI) development process.

Although the important digitalisation that invested the footwear sector during the last years, regarding the foot diagnosis, the shoe/insole design and manufacturing, there is still the lack of a tool that can integrate all the devices (3D scanners, baropodometric platforms, CAD/CAM tools) and users (clinicians, patients and manufacturers) involved in the process. For this reason, insoles manufacturing companies and orthopaedic centres are still forced in using handicraft procedures (Mandolini et al., 2015), based on subjective knowledge of skilled podiatrists and manual exchange of hard copy documents, that conduct to design/manufacturing errors and delays.

The research activities for the custom-made insole sector are currently focused on the design phase, 3D modelling in particular. Orthopaedic technicians are currently supported by dedicated and stand-alone 3D modelling CAD systems (Mandolini et al., 2015) and software systems for selecting the materials for each part of the product (Mandolini et al., 2013). However, these systems do not contain the knowledge to address the overall patients' needs. In fact, in literature, it is assumed that a CMI can contribute to positive effects on patient's foot and general health, including quality of life and return to normal daily activities, only if appropriately designed (Amer et al., 2013).

Customised foot orthotic insoles form the interface between the foot and the shoe, managing the forces distribution between the shoe sole and foot sole. The insoles are considered "customised" if specific data from the patient foot is used in the design process, typically foot shape and pressure distribution. Orthotic insoles can be prescribed for the treatment or prevention of a wide range of foot and lower limb problems with several potential aims. 
Generally, the current design practice is very susceptible to individual practitioners' tacit knowledge (mainly experience) and the field of application of the CAD systems, mentioned above, is limited to the 3D modelling phase. Therefore, they cannot be considered as tools supporting the whole development process. Authors have recently reported how this leads to a "trial and error" approach to orthotic practice (Williams et al., 2016). Furthermore, practitioners are currently working with several devices (3D scanners, 3D modelling systems, material selection software, etc.), which are not connected nor these ones support the cooperation among the stakeholders.

The collaborative design is a key aspect for improving the design process of a footwear in general. Head and Porter (2011) developed a co-design toolkit for in-store personalisation service, which collects customers' data through questionnaires and foot scans, and supports them in choices such as uppers, colours, midsole and insole. In addition, others offer the opportunity to create personalised footwear in terms of fit, function and design, in specialised retail stores or at selected events. This connects the point of sale with the manufacturing systems (Berger and Piller, 2003). Both cases refer to the retail footwear sector.

For orthopaedic footwear, the prescription process consists of collaboration between the final user and the orthopaedic technician and it is based on the exchange of clinical, biomechanical and subjective aesthetics information (Gonzalez et al., 2012). A digital and web-based system for the selection of the shoe model based on person specific information has been developed for defining and ordering customised therapeutic footwear (Calzamedi, 2014). This platform is directly connected with a CAD software for shoe last design. However, this system does not address the issue of CMI prescription, design and manufacturing.

The work presented in this paper aims to overcome the state of the art, introducing a multi-user platform that integrates all the devices used by clinicians and manufacturers, and that allows the communication between all the stakeholders involved in the CMI development process. In this paper, the attention will be focused on the platform's module oriented to the clinician, thus on the knowledge-based method which drives and helps him/her in the prescription process.

\section{Research method}

This section presents the research method used to design the platform, by pointing out the requirements analysis, the platform design and development, the test and the study of the results.

Based on discussions with practitioners via focus groups, which are portrayed in detail elsewhere (Williams et al., 2016), a specification for a digital platform to support prescription, design and manufacture of CMI has been developed. This specification identified the platform users, use scenarios, and requirements.

\subsection{Users}

The multi-user platform considers four stakeholders:

- The final customers (patients), who will wear the CMI, are increasingly curious in understanding their own health and expect participation in selection of products and defining preferred health care interventions. The patient has also a critical role in providing feedbacks and thus measurements of health outcomes due to CMI use.

- The practitioners have multiple requirements. They interact with the final users (patients) and have an aspiration to demonstrate them the importance of the product and its features. Through this platform, they may educate and engage the final user. In addition, the platform can add value to the practitioners practice by supporting decisions such as material choices, by driving compliance with best practices and by speeding up prescription processes.

- The manufacturers, who produce the CMI, require that foot and prescription data is standardised in quality and format, and integrates well with the CAD and CAM stages of production.

- The controller, who could be the chief of a group of CMI practitioners working for the same private company or a public health organisation (e.g. Head of a Physical Therapy department), is searching for new methods and tools to improve quality of care. They want to demonstrate how 
staff meets recognised standards of best practice, manage variations in practice between practitioners, measure the benefits from the services they manage, and manage costs.

\subsection{Use scenarios}

Four use scenarios have been identified:

- The first is the sequence by which CMI design process occurs, such as capture/uploading of foot data, specification on main design features, followed by specification of minor features.

- The second is the process by which patients would provide feedback, including use of a unique identifier for each patient and how changes in health status could be measured, including the number of questions and mode of responses.

- The third use scenario is how a controller would review prescriptions by their staff/department, what data is required and what approaches for stratifying data (e.g. by individual staff member, of by patient or CMI type).

- Finally, the fourth use scenario is a process by which practitioners could capture their preferred CMI designs as template that they could rapidly draw upon in the prescription process. These CMI design templates might represent the vast majority of their practice, or a high percentage of the CMI features they rely upon routinely. Thus, standardization of these common designs could speed up the prescription process and reduce risk of errors too.

\subsection{Platform specifications}

The platform was primarily thought for the practitioner to enter and validate CMI prescriptions. Therefore, a series of platform specifications has been defined:

- The platform has to connect the foot and patient biomechanical properties with the insole features and related parameters: definition of several strict configuration/prescription rules by gathering and combining guidelines of the podiatric medicine and insole geometric rules. These configuration rules make the platform a knowledge intensive tool.

- The platform has to speed up and simplify the prescription process: definition of pre-configured insoles template such as "sport activity" or "early diabetes", with specific values of insole features and parameters.

- The platform has to manage the steps through which a practitioner works but also to check for incomplete or contradictory data/requests and thus to validate prescriptions. It can likewise look to capture common practices either by a specific clinician or based on externally validated guidelines/evidence based on CMI design.

- The outcome of the insole prescription platform has to be connected to a CAD system in order to support conversion of the prescription data into a virtual geometric model of the CMI and thus into a product that can be manufactured.

- The four user interfaces (one for each actor of the insole development process) have to be simple and friendly.

\subsection{Platform development}

The multi-user collaborative platform has been developed on Microsoft .NET Framework, with its own database (Microsoft SQL Server) that stores:

- Configurations rules

- Insole templates with the values of every feature

- Prescriptions configured by the podiatrists

- Users and relative information (including patients)

- Feedbacks given by patients

- Instructions and advices supporting the configuration process

The CMI order is an XML standard file which is shared through the whole insole development process. In order to limit its dimension, the XML file contains only the main information related to the custom made insole, with pointers to the records of the databases of the tools connected with the platform (such 
as CAD tools, etc.). The Web Services technology has been used for the data exchange and synchronization among the databases.

\subsection{Test and results analysis}

The proposed knowledge-based software platform has been tested within an Italian Health Facility. The objective of the test was to evaluate the usability and completeness of the system and to measure the quality and robustness of the CMI templates and configuration rules. A questionnaire has been submitted to practitioners and patients. The results showed that the platform was globally appreciated.

\section{The CMI prescription process supported by a web platform}

\subsection{Prescription process for a custom-made insole}

The CMI prescription and configuration process, proposed in this paper, is made by a sequence of simple and standardised steps with the aim of supporting the practitioners work. Patients are involved in the evaluation of the CMI, controller is able to monitor processes and manufacturers receive the electronic insole order. This process has been supported and integrated within a dedicated software platform, called Smart Prescription System (SPS).

The proposed prescription and manufacturing process consists of the following steps:

1. The practitioner analyses the patient clinical status, clinical history and foot condition. After that, the data is uploaded into the SPS, including any electronic files of 3D foot shape, pressure analysis or pictures. SPS is thus a gateway and digital repository for all the information required to commence design of a CMI.

2. The practitioner prescribes a new CMI taking into consideration all the data acquired and he is supported by the knowledge inside the software system. The software platform uses previous choices and the data input to automatically suggests the most appropriate template for that patient, based on foot size for example, but also any medical or other person specific data input (e.g. pathology). However, the practitioner could adjusts the choice in terms of CMI geometry and materials. Before confirming the CMI prescription, the software application checks the prescription by executing the general validation rules stored into its database. The customers can see the 3D CMI virtual model, in real-time and with a photo-realistic render of surfaces.

3. During the prescription process in (2), the practitioner can also save the current prescription as a new user defined template. This feature allows clinicians to retrieve a prescription made for another patient that might be appropriate for the current one. In this manner, the platform offers an opportunity to reduce the prescription time where complex designs are used for many patients.

4. The practitioner can also add instructions during this phase, showcasing links to validated healthcare web sites to educate the patient about his clinical condition and discuss with him on issues related to health behaviour (e.g. footwear choices, physical activity management). Here the focus is on promoting self-monitoring and self-management.

5. The practitioner then activates an evaluation section in the software, which allows capturing the CMI performance and pathology progression over the time. The patient will complete questions online at intervals they themselves decide and at their convenience. In addition to standard questions, patient specific questions can also be developed by the podiatrist.

6. At the end of the prescription process, the practitioner confirms the CMI prescription, which represents the commercial order with a manufacturer/provider of the CMI. An XML file (electronic clinical prescription) that holds the CMI and relevant patient information, together with all the electronic files created during the process and required for the insole manufacturing, are automatically sent to the CMI manufacturer. This file can also be sent to a footwear selection or prescription system, for designing or selecting a footwear that can accommodate the CMI.

7. In the factory, a technician will be connected to the SPS and, by using a dedicated 3D CAD system, he creates the 3D model of the CMI. The CAD software tool reads the XML file and automates the 3D modelling steps so that the technician's role is more related to checking/improving the result rather than modelling the entire design starting from the CMI specifications. 
8. Once CMIs have been manufactured, these ones are fitted into the patient footwear by the practitioner, or perhaps sent direct to the patient by the manufacturer. The patient is then able to go online and complete the pre-agreed questionnaire that captures health outcomes. The practitioner can be alerted for the feedback being provided by the patient and respond accordingly if, for example, progress is not as expected. Practitioner can then remotely plan future clinical appointments, modifications to the design, manufacture further CMIs, and so on.

9. By analysing the patient feedback and the prescriptions completed by multiple practitioners, the controller can extract statistics, to evaluate, for instance, variation in practices over time, for specific patient groups, or across a team of practitioners. This data can then be used to drive innovation in education and training for staff, service delivery, but also evidencing the health outcomes delivered by the practitioners in the service.

Figure 1 presents the workflow afore described. The blocks with thick borders represent the modules of the SPS, the arrows with solid line indicate the exchange of electronic data among workflow phases, and the arrows with dotted line represent communications between the software modules. Each software module is detailed described in the Section 3.3.

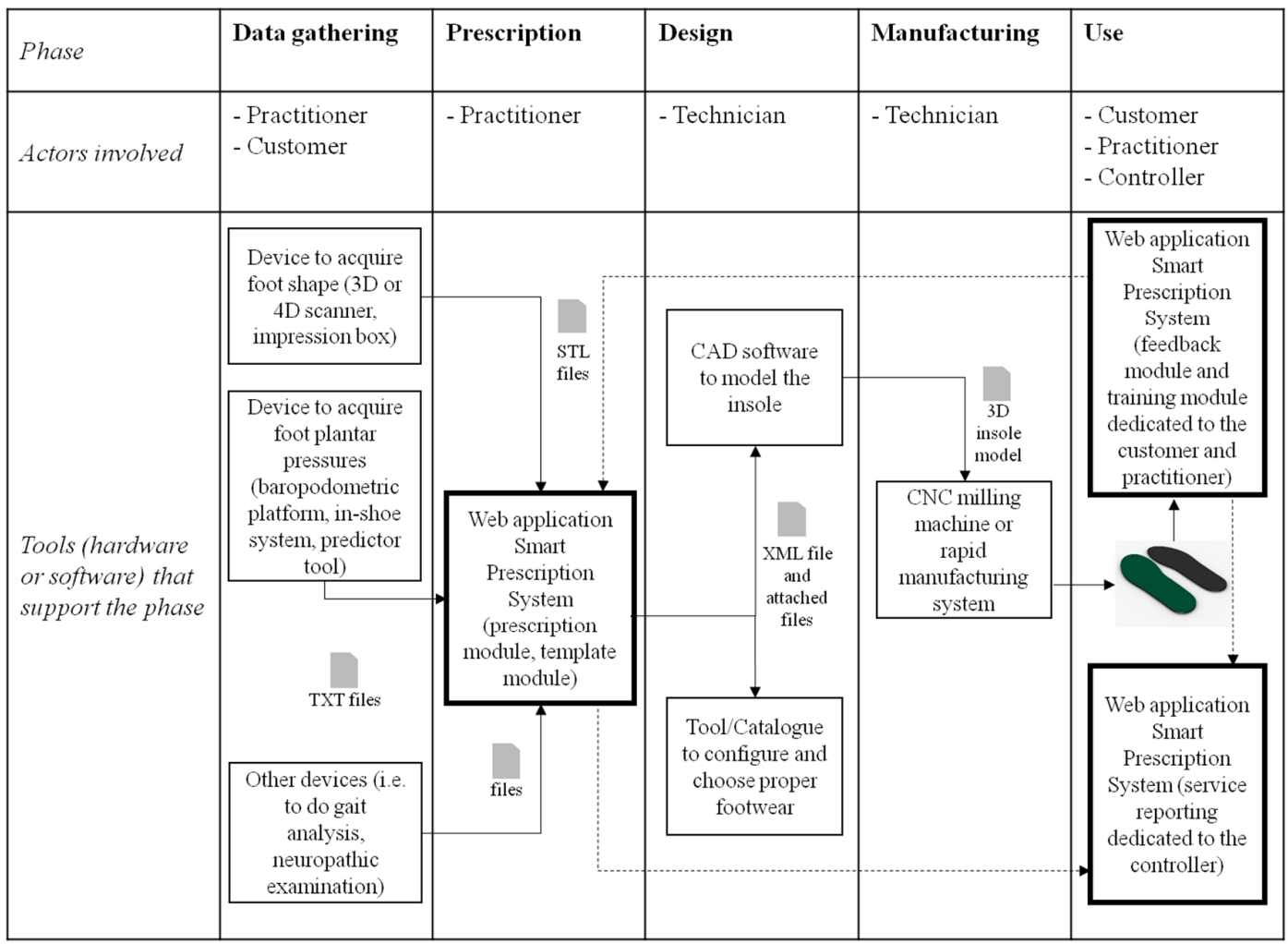

Figure 1. The proposed process to configure a custom made insole

\subsection{CMI features and configuration rules}

The CMI configuration process uses the SPS and a database of design features, with rules related to each feature (Benard et al., 2004). This "knowledge" integrated in the SPS consists of several configuration rules that connect the foot and patient properties with the CMI design choices. According to the literature, the insole features are divided in two groups: insole main features (Healy et al., 2010), that are geometry and material features and "forefoot additions" (Nicolopoulos et al., 2000).

Hereunder the list of the insole main features:

- Model: it is the type of the insole, linked to the insole length.

- Main shell: it refers to the body of the insole. It gives the right support to the patient's foot, thanks to the suitable thickness of a specific material. 
- Top cover: it is a thin layer in contact with the foot, commonly made of breathable, antibacterial and antimicrobial material used to avoid the proliferation of infections.

- Medial heel wedge: it is the wedge located on the internal side of the heel. It is used to tilt the heel outwards, and to compensate flat and valgus or pronated feet.

- Lateral heel wedge: it is the wedge located on the external side of the heel. It is used to tilt the heel inwards, and to compensate varus or supinated feet.

- Arch height: it is the distance measured between the highest part of the insole and the ground.

- Heel raise: it is the wedge that has maximum height under the heel and goes decreasing towards the midfoot.

The forefoot additions (Hayda et al., 1994; Deshaies et al., 2011) are commonly spit in two groups: addition of material (metatarsal bar, metatarsal dome and cushion) and removal of material (metatarsal cavity and cut out). Each one is defined by its height or depth and spatial position along the foot.

To facilitate the CMI prescription phase, the authors defined the Insole Template concept, a preconfigured CMI with specific values for each insole feature. The template aims to satisfy the common patient needs in accordance to the foot biomechanical properties. Pre-defined templates are, for example, "early diabetes", "neuropathic foot" and "sport activity".

The CMI features and additions have linked each other by several prescription rules that support good practice. Table 1 contains the most important ones, split in assignment rule (for assigning a value to a feature), check rule (to verify if the feature value is included into a range) and alert (warning message to the practitioner). During the prescription phase, the application checks systematically if the insole respects these rules to guarantee the final quality and thus support the practitioner's work.

Table 1. Insole prescription rules

\begin{tabular}{|c|c|}
\hline Prescription Rules & Type of rule \\
\hline If Model Is $3 / 4$ Length Then Total Thickness Forefoot $=0$ & Assignment \\
\hline If Model Is 3/4 Length Then Material of Main Shell = Polypropylene & Assignment \\
\hline $\begin{array}{l}\text { If Model Is Full Length Then } \\
\text { Thickness of Main Shell = Total Thickness Forefoot - ( } \sum \text { (Thickness of all layers in the top } \\
\text { cover) + Height of Forefoot Cushion) }\end{array}$ & Assignment \\
\hline If model Is $3 / 4$ Length Then Metatarsal Bar $=$ null & Assignment \\
\hline If model Is $3 / 4$ Length Then Metatarsal Dome $=$ null & Assignment \\
\hline If model Is $3 / 4$ Length Then Metatarsal Cavity $=$ null & Assignment \\
\hline If model Is $3 / 4$ Length Then Metatarsal Cut out $=$ null & Assignment \\
\hline If model Is $3 / 4$ Length Then Forefoot Cushion $=$ null & Assignment \\
\hline If Metatarsal Bar Isnot null Then Metatarsal Dome $=$ null & Assignment \\
\hline If Metatarsal Dome Isnot null Then Metatarsal Bar = null & Assignment \\
\hline If Model Is Full Length Then Total Thickness Forefoot $>0$ & Check \\
\hline $\begin{array}{l}\text { If Model Is } 3 / 4 \text { Length Then } \\
\text { (Thickness of Main Shell } \leq 3 \mathrm{~mm} \text { AND Thickness of Main Shell > 2) }\end{array}$ & Check \\
\hline If Model Is Full Length Then Material Density of Main Shell $>0$ & Check \\
\hline If Model Is Full Length Then Thickness of Main Shell > $1 \mathrm{~mm}$ & Check \\
\hline$-6 \mathrm{~mm} \leq$ Arch Height $\leq 6 \mathrm{~mm}$ & Check \\
\hline$\sum$ (Thickness of all layers in the top cover) $<$ Total Thickness Forefoot & Check \\
\hline $\begin{array}{l}\text { If Forefoot cushion Isnot null Then } \\
\left.\text { Height of Forefoot Cushion }+\sum \text { (Thickness of all layers in the top cover }\right)<\text { Total Thickness } \\
\text { Forefoot }\end{array}$ & Check \\
\hline $\begin{array}{l}\text { If Metatarsal Cavity is not null AND Metatarsal Cut Out is not null Then } \\
\text { Position of Metatarsal Cavity } \neq \text { Position of Metatarsal Cut Out }\end{array}$ & Check \\
\hline $\begin{array}{l}\text { If Total Thickness Forefoot } \geq 5 \mathrm{~mm} \text { Then } \\
\text { Alert (The shoe may not have space for the insole) }\end{array}$ & Alert \\
\hline
\end{tabular}




\subsection{Smart Prescription System: The web platform}

The Smart Prescription System is a web application based on a database for storing the patients, the insole templates, the prescription rules, the prescriptions configured by the practitioner and the feedback given by patients. The web application has four interfaces, one for each user listed in Section 2.1. The system is made of different modules and each user has access to appropriate parts of the application according to their role and function. Table 2 contains, for each module, a general description and the functions available to each category of users.

Table 2. The functions available in each software module for the four users, practitioner, customer, controller and manufacturer

\begin{tabular}{|c|c|c|c|c|}
\hline & Practitioner & Customer & Controller & Manufacturer \\
\hline 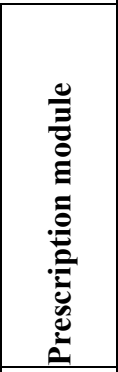 & $\begin{array}{l}\text { View details of a patient; } \\
\text { Insert new patient; } \\
\text { View details of an insole } \\
\text { already prescribed; } \\
\text { View feedbacks given by } \\
\text { patients; } \\
\text { Prescribe a new insole; } \\
\text { Use the 3D viewer to view } \\
\text { the insole 3D model; }\end{array}$ & $\begin{array}{l}\text { View, modify and save } \\
\text { personal data; } \\
\text { View personal insoles; }\end{array}$ & - & - \\
\hline 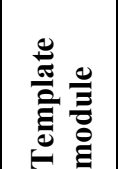 & $\begin{array}{l}\text { View values of an insole } \\
\text { template; } \\
\text { Configure and save a new } \\
\text { user-defined insole template; }\end{array}$ & - & - & - \\
\hline 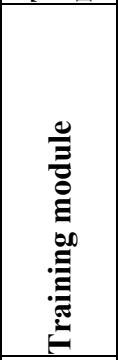 & $\begin{array}{l}\text { Links to institutional and } \\
\text { medical web sites (page } \\
\text { "Community"); } \\
\text { Configure customised } \\
\text { institutional and medical web } \\
\text { sites and other custom } \\
\text { information for each patient; }\end{array}$ & $\begin{array}{l}\text { Links to institutional } \\
\text { and medical web (page } \\
\text { "Community"); } \\
\text { Personalized } \\
\text { instructions and advice } \\
\text { for the daily life; } \\
\text { Educational part about } \\
\text { their foot conditions and } \\
\text { insole features; }\end{array}$ & - & - \\
\hline 导 & $\begin{array}{l}\text { Configure customized } \\
\text { feedback questionnaire for } \\
\text { each patient; }\end{array}$ & $\begin{array}{l}\text { Give personal feedbacks } \\
\text { to a prescription, after } \\
\text { receiving an automatic } \\
\text { reminder by email/sms; }\end{array}$ & - & - \\
\hline 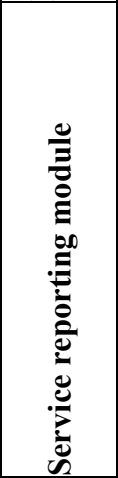 & - & - & $\begin{array}{l}\text { Monitor the work of } \\
\text { practitioner/ } \\
\text { clinicians, in terms of: } \\
\text { Number of visits } \\
\text { Most used insole } \\
\text { templates } \\
\text { Trend in prescribing } \\
\text { new insoles } \\
\text { Feedbacks from } \\
\text { patients } \\
\text { Request of new Insole } \\
\text { templates }\end{array}$ & - \\
\hline 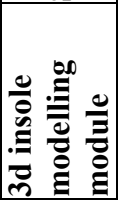 & - & - & - & $\begin{array}{l}\text { Receive the } \\
\text { electronic insole } \\
\text { order (design } \\
\text { with a CAD } \\
\text { system) }\end{array}$ \\
\hline
\end{tabular}


The module for the prescription of a new CMI is the most important for the Smart Prescription System. For this reason, to simplify and speed up the practitioner's work, it is split into the following software sub-modules, accessed through a wizard procedure:

- patient data: to insert patient information and upload files from external tools such as 3D foot scanners or digital photos;

- template selection: from the list of the insole templates, the tool suggests the most suitable template for that patient or, alternatively, the practitioner can choose a different one;

- customisation of insole features: to personalize the chosen template, changing geometry and materials (Figure 2);

- customisation of the CMI forefoot additions: to add, change or remove forefoot additions (geometry and materials);

- prescriptions customization: to review, save and confirm the prescription as a new insole order, produce the XML file to support manufacturing, and save the prescription as a new practitioner defined template.

\section{Patients \\ Insoles , \\ Templates • \\ Community}

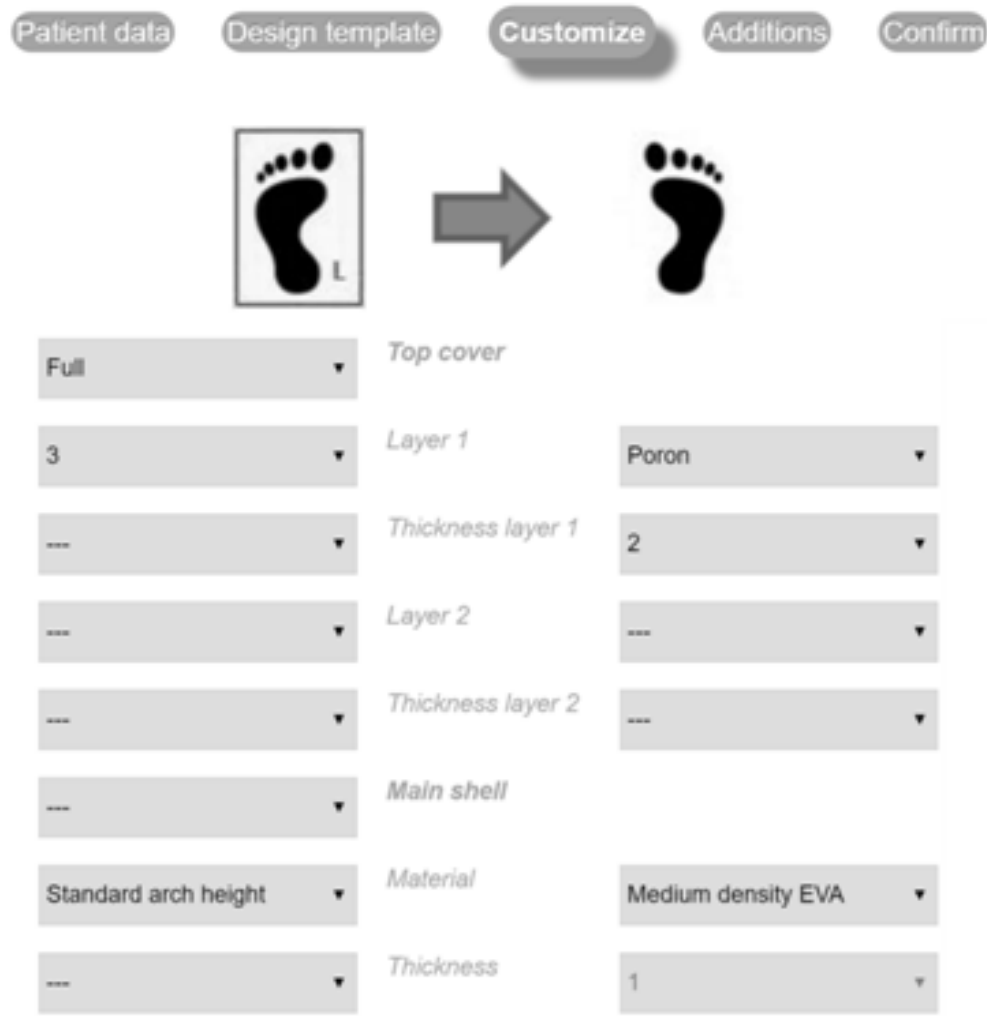

Figure 2. A screenshot of the Smart Prescription System

\section{Web platform preliminary test and results discussion}

\subsection{Testing protocol and participants}

The proposed new process and related software platform have been tested within the orthopaedic department of an Italian Health Facility. A research team made by two research fellows supported the test phase. This preliminary test aimed at evaluating the usability and completeness of the system and at measuring the quality and robustness of the CMI template and configuration rules. The questionnaire distributed to the practitioners consisted of the following sections:

- Ease of use: evaluation of the tool usability and graphics; 
- Functionality: evaluation of the functionalities in each software module and its ability to achieve its purpose;

- Navigation and language: evaluation of the system graphical layout, and the availability of additional languages and user manuals/tutorials;

- Error prevention: evaluation of the ability of the system to prevent errors, during the prescription process and evaluation of the appropriateness of the insole prescription and selection rules (e.g. ability of the tool to select the best template for the patient).

The questionnaire distributed to the patients contained the same sections of the practitioner's questionnaire, except for the section "error prevention". The testers used a 10-point scale: zero if the tool did not meet minimal requirements and 10 if the tool fully satisfied the requirements.

The practitioners involved in the Italian Health Facility (see Table 3 for details) used the system for two months, after a specific training, following the design process for the CMIs prescription. The researchers trained the practitioners and supported them during the use. Patients were chosen to offer some variability in gender, age and pathology (Table 4).

Table 3. Practitioners and researcher's profiles

\begin{tabular}{|l|l|l|l|l|}
\hline $\begin{array}{l}\text { User } \\
\text { ID }\end{array}$ & Gender & Age & Degree & Job \\
\hline 1 & Female & 28 & $\begin{array}{l}\text { Master degree in Biomedical Engineering. Research fellow } \\
\text { at University }\end{array}$ & $\begin{array}{l}\text { Researcher } \\
\text { Assistant }\end{array}$ \\
\hline 2 & Male & 32 & Degree in podiatry. Freelance within a medical office. & Junior Practitioner \\
\hline 3 & Male & 50 & $\begin{array}{l}\text { Degree in general medicine and surgery. Doctor at the } \\
\text { diabetic foot department of a hospital }\end{array}$ & $\begin{array}{l}\text { Senior } \\
\text { Practitioner }\end{array}$ \\
\hline 4 & Female & 29 & Sensing device designer. Research fellow at University & Researcher \\
\hline 5 & Male & 62 & $\begin{array}{l}\text { Medicine and Surgery. Diabetic foot department director of } \\
\text { a hospital }\end{array}$ & $\begin{array}{l}\text { Senior } \\
\text { Practitioner }\end{array}$ \\
\hline 6 & Female & 34 & $\begin{array}{l}\text { Podiatry, Master in Diabetic Foot. Freelance within a } \\
\text { medical office. }\end{array}$ & Junior Practitioner \\
\hline
\end{tabular}

Table 4. Profile of the twenty patients involved in the test

\begin{tabular}{|l|l|l|}
\hline Sex: $\mathbf{N}^{\circ}$ patients & Male: 10 & Female: 10 \\
\hline \multirow{3}{*}{ Age: $\mathbf{N}^{\circ}$ patients } & under 30: 2 & under 30: 3 \\
& $31-60: 5$ & $31-60: 4$ \\
& Over 60: 3 & Over 60: 3 \\
\hline \multirow{2}{*}{ Range of BMI: $\mathbf{N}^{\circ}$ patients } & $19-24,99: 7$ & $19-24,99: 8$ \\
& $25-29,99: 3$ & $25-29,99: 2$ \\
\hline \multirow{3}{*}{ Level of activity: $\mathbf{N}^{\circ}$ patients } & Low: 1 & Low: 6 \\
& Normal: 5 & Normal: 2 \\
& Active: 4 & Active: 2 \\
\hline \multirow{5}{*}{ Disease: $\mathbf{N}^{\circ}$ patients } & clubfoot: 3 & hammer toes: 2 \\
& pes cavous: 1 & flat foot: 2 \\
& hallux valgus: 2 & hallux valgus: 2 \\
& early diabetic foot: 3 & early diabetic foot: 3 \\
& neuropathic foot: 1 & neuropathic foot: 1 \\
\hline
\end{tabular}

\subsection{Results and discussion}

The results were gathered from six experts (practitioner and researchers) involved in the Health Facility and from twenty patients (see Figure 3). Technicians and controller were not involved in this preliminary test. The results highlight that the Smart Prescription System was globally appreciated as demonstrated by the average score (higher than seven). The lowest score was recorded in the section "error prevention" 
because, generally, the medical staff were not accustomed to being guided and controlled by rules. All practitioners used the insole templates during the test phase with small modifications: only five insoles among a total of twenty did not correspond to the pre-built and automatically selected templates. The software tool was found to be flexible and easy to use. General comments on the platform reveal that clinicians noted several advantages in the proposed prescription approach and related system. The first was the value of the insole templates, especially the support provided by the set of rules, perhaps essential for inexperienced clinicians. Some practitioners have stated that the rules simplify and advance significantly the ability of the CMIs to meet patients' needs and avoids mistakes due to inexperience or oversights. The standardized procedure for prescription and its link to CAD guarantees the repeatability of the result and the quality of the final product for the customer.

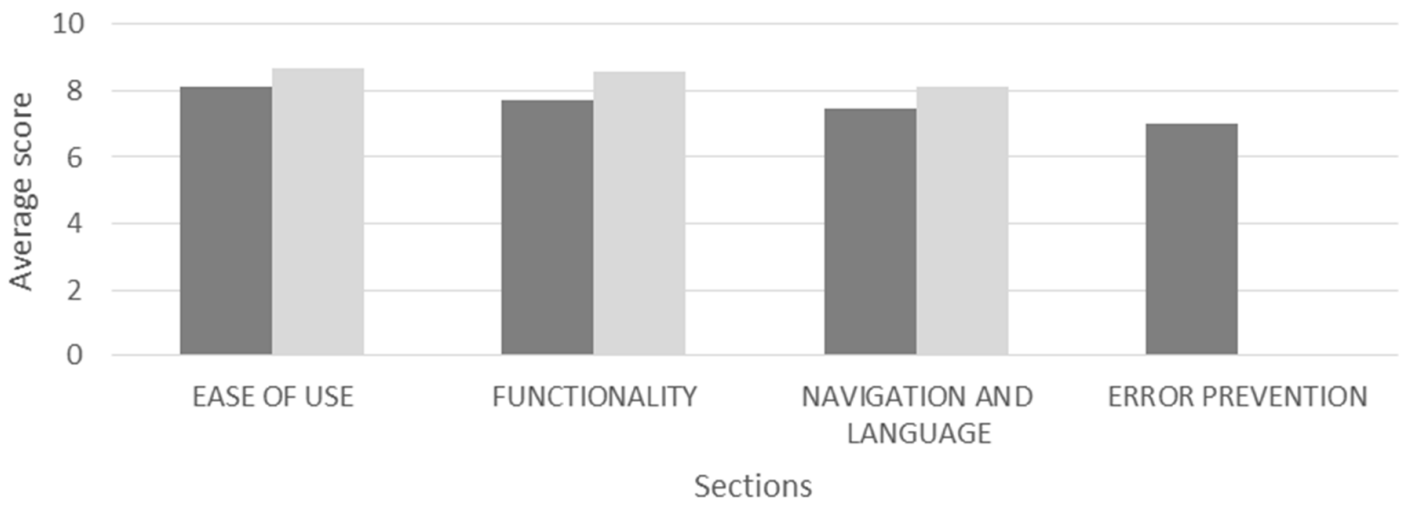

- Practiotioner Interface $\quad$ Customer Interface

Figure 3. Results of the preliminary test

Clinicians estimated a reduction of non-complaints insoles from $10 \%$, with the traditional approach (without using the web-platform), up to $2 \%$, using the proposed system, one year after the introduction of such platform. Despite the presence of rules, the practitioner is still responsible for the prescription he did.

Patients involved during tests praised the system (Figure 3). Clinicians and patients appreciated the opportunity to collect feedback. It allowed practitioners to be involved in remote monitoring of outcomes and thus to evaluate the effectiveness of CMIs.

\section{Conclusions}

The paper illustrated a method for prescribing custom-made insoles for patients with pathologies and not, in a user-friendly environment, through a web application (Smart Prescription System), a knowledge-based system that helps and guides the practitioner, speeding up and standardizing his work. The proposed platform has modules and functions primarily focused on practitioners, respecting the needs of controllers, final customers/patients and manufacturers. This approach represents a step toward the changeover from the traditional (handmade) to the innovative (digital) process.

The proposed web application has been tested with practitioners and patients. The good results demonstrated overall satisfaction of all users. Future work will be focused on the improvement of the configuration rules and the development of an advanced feedback module for supporting a self-decisionmaking process. Moreover, the authors will develop a protocol for the validation of the configuration rules, involving a larger set of stakeholders (around 20) and patients (around 100).

\section{References}

Amer, A.O., Jarl, G.M. and Hermansson, L.N. (2013), "The effect of insoles on foot pain and daily activities", Prosthetics and Orthotics International, Vol. 38 No. 6, pp. 474-480. https://doi.org/10.1177/0309364613512369 
Benard, M.A., Goldsmith, H., Gurnick, K.L., Jarrett, B., Kase, B. et al. (2004), Prescription Custom Foot Orthoses Practice Guidelines, The American College of Foot and Ankle Orthopedics and Medicine (ACFAOM), Bethesda, Maryland, USA.

Berger, C. and Piller, F. (2003), "Customers As Co-Designers”, Manufacturing Engineer, Vol. 82 No. 4, pp. 4245. https://doi.org/10.1049/me:20030407

Calzamedi (2014), FASHION-ABLE: development of new technologies for the flexible and eco-efficient production of customized healthy clothing, footwear and orthotics for consumers with highly individualized needs. D5.4 Samples of customised shoes for addressed target groups through the involvement of final consumers, Calzamedi.

Deshaies, A., Roy, P., Symeonidis, P.D., LaRue, B., Murphy, N. and Anctil, E. (2011), "Metatarsal bars more effective than metatarsal pads in reducing impulse on the second metatarsal head", The Foot, Vol. 21 No. 4, pp. 172-175. https://doi.org/10.1016/j.foot.2011.05.001

Gonzalez, J.C., Olaso, J., Gill, M., Puigcerver, S., Dural, J.V. and Lopez, I. (2012), "FASHION-ABLE: needs and requirements for clothing, footwear and orthotics of consumers groups with highly individualised needs", Proceedings of the 18th International Conference on Engineering, Technology and Innovation (ICE 2012), Munich, Germany, June 18-20, 2012, IEEE. https://doi.org/10.1109/ICE.2012.6297700

Hayda, R., Tremaine, M.D., Tremaine, K., Banco, S. and Teed, K. (1994), "Effect of Metatarsal Pads and Their Positioning: A Quantitative Assessment”, Foot \& Ankle International, Vol. 15 No. 10, pp. 561-566. https://doi.org/10.1177/107110079401501008

Head, M. and Porter, C.S. (2011), "Developing A Collaborative Design Toolkit For The Personalisation Of Running Shoes", Design Principles And Practices, Vol. 5 No. 6, pp. 303-325. https://doi.org/10.18848/1833$1874 / \mathrm{cgp} / \mathrm{v05i06/38232}$

Healy, A., Dunning, D.N. and Chockalingam, N. (2010), "Materials used for footwear orthoses: a review", Footwear Science, Vol. 2 No. 2, pp. 93-110. https://doi.org/10.1080/19424280.2010.486045

Mandolini, M., Carloni Vitali, M., Macchione, A., Raffaeli, R. and Germani, M. (2015), “A CAD Tool to Design Bespoke Insoles for Severe Orthopaedic Treatments", Computer Aided Design and Applications, Vol. 12 No. 6, pp. 700-709. https://doi.org/10.1080/16864360.2015.1033333

Mandolini, M., Germani, M. and Raffaeli, R. (2013), "A Finite Element Method to support the materials selection phase during the insole design process", Proceedings of the 23th International Conference on Graphic Engineering (INGERGRAF-ADM-AIP-PRIMECA 2013), Madrid, Spain, June 19-21, 2013.

Nicolopoulos, C.S., Black, J. and Anderson, E.G. (2000), "Foot orthoses materials", The Foot, Vol. 10 No. 1, pp. 1-3. https://doi.org/10.1054/foot.1999.0531

Williams, A.E., Martinez-Santos, A., McAdam, J. and Nester, C.J. (2016), “'Trial and error...', '...happy patients' and '... an old toy in the cupboard': a qualitative investigation of factors that influence practitioners in their prescription of foot orthoses", Journal of Foot and Ankle Research, Vol. 9 No. 1. https://doi.org/10.1186/s13047-016-0142-9

Agnese Brunzini, PhD Student

Università Politecnica delle Marche, Department of Industrial Engineering and Mathematical Sciences

Via Brecce Bianche 12, 60131 Ancona, Italy

Email: a.brunzini@staff.univpm.it 
